\title{
Penerapan PHBS dengan peningkatan pengetahuan dan sikap melalui pendekatan keluarga di Desa Gaji Kabupaten Demak
}

\author{
${ }^{1}$ Siti Thomas Zulaikhah ${ }^{*}$; ${ }^{1}$ Ratnawati; ${ }^{1}$ Joko Wahyu Wibowo; ${ }^{1}$ Muhammad Ulil Fuad; \\ ${ }^{1}$ Elly Noerhidayati; ${ }^{1}$ Erwin Budi Cahyono; ${ }^{1}$ Muhammad Saugi Abduh; ${ }^{1}$ Lusito \\ ${ }^{1}$ Prodi Kedokteran, Fakultas Kedokteran, Universitas Islam Sultan Agung, Semarang, Indonesia \\ *Corresponding author:
}

Jl. Raya Kaligawe KM. 4 PO BOX 1054 Semarang Jawa Tengah Indonesia Telp. (+6224) 65833584, Fax (+6224) 6594366

Email: sitithomas@unissula.ac.id
Received:
Revised:
Accepted:
Published:
11 August 2019
20 November 2019
20 November 2019
30 November 2019

\begin{abstract}
Abstrak
Derajat kesehatan merupakan salah satu unsur penting dalam upaya peningkatan Indeks Pembangunan Manusia (IPM) bangsa Indonesia. Sementara itu, derajat kesehatan tidak hanya ditentukan oleh pelayanan kesehatan, tetapi yang lebih dominan justru adalah kondisi lingkungan dan perilaku masyarakat. Upaya untuk meningkatkan perilaku masyarakat agar mendukung peningkatan derajat kesehatan dilakukan melalui program pembinaan Perilaku Hidup Bersih dan Sehat (PHBS). Perilaku Hidup Bersih dan Sehat (PHBS) merupakan upaya untuk memberdayakan anggota keluarga agar tahu, mau dan mampu melaksanakan PHBS serta berperan aktif dalam gerakan kesehatan di masyarakat. Kesadaran masyarakat akan kesehatan dan pola hidup bersih sehat, khususnya masyarakat desa masih sangat rendah. Peningkatan pengetahuan dan sikap terkait Perilaku Hidup bersih sehat diharapkan dapat menjadi upaya menyadarkan masyarakat akan pentingnya melakukan upaya perilaku hidup bersih dan sehat dalam kehidupan sehari-hari sekaligus memberikan gambaran bagaimana cara merealisasikannya sehingga bisa terwujud masyarakat yang peduli terhadap kesehatan.Target yang ingin dicapai adalah terwujudnya peningkatan pengetahuan dan sikap terhadap PHBS sehingga masyarakat mempunyai kemampuan mempraktekkan pola hidup bersih dan sehat secara mandiri. Metode yang digunakan adalah dengan memberikan penyuluhan, pemeriksaan kesehatan, praktek cuci tangan yang benar dan talkshow. Peserta adalah masyarakat di desa Gaji yang diwakili oleh ibu/istri dari setiap KK yang merupakan Pasangan Usia Subur (PUS), berjumlah 60 orang yang diambil secara cluster random sampling. Peserta diberikan pretes pada awal kegiatan dan postes pada akhir kegiatan sebagai evaluasi terhadap kegiatan yang dilaksanakan. Hasil kegiatan terjadi peningkatan pengetahuan dan sikap tentang PHBS, terlihat skor sesudah kegiatan lebih tinggi dibandingkan dengan sebelumnya (perbedaan rerata skor pengetahun sebelum dan sesudah kegiatan 24,16; sedang perbedaan rerata skor sikap sebelum dan sesudah kegiatan 23 , 9. Peserta juga mampu mempraktekkan cuci tangan dengan 6 langkah secara benar.
\end{abstract}

Kata kunci: PHBS; pengetahuan; sikap; keluarga 


\begin{abstract}
Health degree is one of the important elements in efforts to increase the Indonesian Human Development Index (HDI). Meanwhile, the degree of health is not only determined by health services, but what is more dominant is the environmental conditions and people's behavior. Efforts to improve community behavior to support the improvement of health status are carried out through the Clean and Healthy Behavior (PHBS) development program. Clean and Healthy Behavior (PHBS) is an effort to empower family members to know, be willing and able to carry out PHBS and play an active role in the health movement in the community. Public awareness of health and a healthy clean lifestyle, especially rural communities, is still very low. Increased knowledge and attitudes related to healthy hygiene behavior is expected to be an effort to make the public aware of the importance of making clean and healthy life behavior efforts in daily life while providing an overview of how to realize it so that people who care about health can be realized. The target to be achieved is the realization increasing knowledge and attitudes towards PHBS so that the community has the ability to practice clean and healthy lifestyles independently. The method used is to provide counseling, health checks, proper hand washing practices and talk shows. Participants are people in the village of Salary, represented by mothers / wives of each KK who are Fertile Age Couples (PUS), totaling 60 people taken by cluster random sampling. Participants are given a pretest at the beginning of the activity and posttest at the end of the activity as an evaluation of the activities carried out. The results of the activity increased knowledge and attitudes about PHBS, seen after the activity score was higher compared to before (the difference in the average score of knowledge before and after the activity 24,16; while the difference in the average attitude score before and after the activity 23, 9. Participants were also able to practice washing hands with 6 steps correctly.
\end{abstract}

Keywords: PHBS; knowledge; attitude; family

\title{
PENDAHULUAN
}

Kesehatan merupakan investasi untuk mendukung pembangunan ekonomi serta memiliki peran penting dalam upaya penanggulangan kemiskinan. Pembangunan kesehatan harus dipandang sebagai suatu investasi untuk meningkatkan kualitas sumber daya manusia sesuai dengan Undang-Undang Nomor 36 Tahun 2009 tentang Kesehatan. Pembangunan kesehatan pada hakekatnya adalah upaya yang dilaksanakan oleh semua komponen bangsa Indonesia yang bertujuan untuk meningkatkan kesadaran, kemauan, dan kemampuan hidup sehat bagi setiap orang agar terwujud derajat kesehatan masyarakat yang setinggi tingginya. Keberhasilan pembangunan kesehatan sangat di tentukan oleh kesinambungan antar-upaya program dan sektor, serta kesinambungan dengan upaya-upaya yang telah dilaksanakan dalam periode sebelumnya.

Derajat kesehatan masyarakat masih belum optimal dan pada hakikatnya dipengaruhi oleh kondisi lingkungan, perilaku masyarakat, pelayanan kesehatan dan genetika. Kalangan ilmuwan umumnya berpendapat bahwa determinan utama dari derajat kesehatan masyarakat, selain kondisi lingkungan, adalah perilaku masyarakat. Dari hasil Riskesdas 2007 diketahui bahwa rumah tangga yang telah mempraktekkan Perilaku Hidup Bersih dan Sehat (PHBS) baru mencapai 38,7\%. Oleh sebab itu, Rencana Strategi (Renstra) Kementerian Kesehatan Tahun 
2010-2014 mencantumkan target 70\% rumah tangga sudah mempratekkan PHBS pada tahun 2014. Persentase Rumah Tangga Ber-PHBS memang merupakan salah satu Indikator Kinerja Utama (IKU) dari Kementerian Kesehatan.

Manusia hidup di berbagai tatanan, yaitu berbagai tempat atau sistem sosial dimana ia melakukan kegiatan sehari-harinya. Di setiap tatanan, faktor-faktor individu, lingkungan fisik dan lingkunngan sosial berinteraksi dan menimbulkan dampak terhadap kesehatan. Oleh sebab itu dapat pula dikatakan bahwa suatu tatanan adalah suatu tempat dimana manusia memanipulasi lingkungan, sehingga menciptakan dan sekaligus juga mengatasi masalahmasalahnya di bidang kesehatan

Pembangunan kesehatan pada hakekatnya adalah upaya yang dilaksanakan oleh semua komponen bangsa Indonesia yang bertujuan untuk meningkatkan kesadaran, kemauan, dan kemampuan hidup sehat bagi setiap orang agar terwujud derajat kesehatan masyarakat yang setinggitingginya (Kemenkes, 2016). Derajat kesehatan merupakan salah satu unsur pentting dalam upaya peningkatan Indeks Pembangunan Manusia (IPM) bangsa Indonesia. Sementara itu, derajat kesehatan tidak hanya ditentukan oleh pelayanan kesehatan, tetapi yang lebih dominan justru adalah kondisi lingkungan dan perilaku masyarakat. Upaya untuk meningkatkan perilaku masyarakat agar mendukung peningkatan derajat kesehatan dilakukan melalui program pembinaan PHBS. Evaluasi keberhasilan pembinaan PHBS dilakukan dengan melihat indikator PHBS di tatanan rumah tangga (Kemenkes, 2011). PHBS merupakan karakter yang harus dibiasakan sejak dini sehingga terbentuk paradigma sehat dalam diri kita yang dapat diaplikasikan dalam kehidupan keluarga dan masyarakat. Program ini bertujuan untuk memberikan pengalaman belajar atau menciptakan suatu kondisi bagi perorangan, kelompok, keluarga, dengan membuka jalur komunikasi, informasi, dan edukasi untuk meningkatkan pengetahuan, sikap, dan perilaku sehingga masyarakat sadar, mau, dan mampu mempraktekkan perilaku hidup bersih dan sehat. melalui pendekatan pimpinan (advocacy), bina sosial (sosial support), dan pemberdayaan masyarakat (empowerment). Dengan demikian masyarakat dapat mengenali dan mengatasi masalahnya sendiri terutama pada tatanannya masing-masing. Namun kenyataannya, PHBS ini belum diterapkan dengan baik dan benar di lingkungan keluarga. Sangat susah memang untuk mengubah kebiasaan buruk menjadi kebiasaan yang baik dan sehat. Cita-cita Indonesia sehat yang ditandai dengan anak-anak yang sehat, cerdas dan terampil harus dimulai dari rumah. Rumah adalah akar pendidikan karakter sehingga menghasilkan Sumber Daya Manusia Indonesia yang beradab. Keluarga sebagai fokus dalam pelaksanaan program Indonesia Sehat dengan pendekatan keluarga. Salah satu fungsi keluarga adalah fungsi perawatan atau pemeliharaan kesehatan (The Health Care Function) adalah untuk mempertahankan keadaan kesehatan anggota keluarga agar tetap memiliki produktivitas yang tinggi. Fungsi ini dikembangkan menjadi tugas keluarga di bidang kesehatan (Kemenkes, 2016)

Pengetahuan merupakan hasil dari tahu, dan ini terjadi setelah orang melakukan pengindraan terhadap objek tertentu. Pengindraan terjadi melalui panca indra manusia yaitu indra penglihatan, pendengaran, penciuman, rasa dan raba. Sebagian besar pengetahuan manusia diperoleh melalui mata dan telinga. Pengetahuan atau kognitif merupakan dominan yang sangat penting untuk tindakan seseorang (Priyoto, 2014). Sikap merupakan reaksi atau respon seseorang yang masih tertutup terhadap suatu stimulus atau objek (Notoatmodjo, 2010). Sikap merupakan konsep yang dapat membantu untuk memahami tingkah laku (Ahmadi, 2009).

Indeks Keluarga Sehat (IKS) adalah perhitungan kedua belas Indikator Keluarga Sehat dari setiap keluarga yang besarnya berkisar antara 0-1, Keluarga yang tergolong dalam Keluarga Sehat adalah keluarga dengan Indeks Keluarga Sehat (IKS) > 0,8 (Kementrian Kesehatan RI, 2016). Pencapaian IKS masih tergolong rendah untuk daerah-daerah di Indonesia, hasil penghitungan IKS dari 9 provinsi sasaran awal (Sumatera Utara, Sumatera Selatan, Lampung, DKI Jakarta, Jawa Barat, Jawa Tengah, Jawa Timur, Banten dan Sulawesi Selatan) per 8 Juni 2017 didapatkan keluarga yang memiliki IKS diatas 0,8 sebesar 0,163 dari 570.326 keluarga 
(Pusdatin, 2018). Kabupaten Demak menduduki urutan ke-13 dari 35 kabupaten dan kota yang ada di Jawa Tengah untuk data cakupan rumah tangga sehat dengan nilai $81,41 \%$ (Dinas Kesehatan Demak, 2016), Salah satu Desa di Kabupaten Demak yang memiliki tingkat IKS tergolong rendah adalah Desa Gaji yang terletak di Kecamatan Guntur. Berdasarkan survei yang dilakukan terhadap masyarakat di RW 4 Desa Gaji Guntur Demak, sebagian besar keluarga belum mencapai indikator keluarga sehat. Hasil survei diperoleh beberapa masalah di antaranya: 52\% anggota keluarga merokok, hanya $42 \%$ ibu yang memberikan ASI Eksklusif, Pasangan Usia Subur (PUS) yang menggunakan alat kontrasepsi hanya 20\%, penderita hipertensi 8,4\% dan penderita TB paru 2,1\% dan keluarga yang menjadi anggota JKN hanya $17 \%$. Kesehatan merupakan hal yang utama dan mendasar, keberhasilan program kesehatan tidak terlepas dari peran masyarakat, maka terbitlah Inpres Nomor 1 tahun 2017 tentang GERMAS yang diprakarsai oleh Presiden RI. Melalui GERMAS, diharapkan agar kerjasama antar sektor dan lintas program menjadi katalisator bagi masyarakat untuk mampu berperilaku hidup sehat, yang pada akhirnya dapat membentuk sumber daya manusia Indonesia yang unggul sehingga menjadi pondasi bangsa Indonesia yang kuat (Kepmenkes, 2016). Melalui Germas, pemerintah khususnya Kemenkes mengajak masyarakat untuk mengubah kebiasaan-kebiasaan yang tidak sehat. Germas mengangkat beberapa aktifitas, antara lain: Melakukan aktifitas fisik, mengonsumsi sayur dan buah, tidak merokok, tidak mengonsumsi alkohol, memeriksa kesehatan secara rutin, membersihkan lingkungan, dan menggunakan jamban. Penelitian yang dilakukan oleh Sulastri et al (2014), menyatakan bahwa terdapat hubungan antara tingkat pengetahuan dengan perilaku anak sekolah tentang hidup bersih dan sehat di sekolah Dasar Negeri Wilayah Puskesmas Selemadeg Timur II $(\mathrm{p}=0,000)$. Penelitian yang dilakukan Zulaikhah (2018) menyatakan bahwa penyuluhan berpengaruh terhadap pengetahuan, sikap dan praktik dalam Pencegahan DBD. Tujuan pengabdian masyarakat ini adalah untuk meningkatkan pengetahuan dan sikap tentang PHBS sehingga indikator keluarga sehat capaiannya meningkat.

\section{METODE KEGIATAN}

Metode kegiatan dalam peningkatan pengetahuan dan sikap tentang PHBS di desa Gaji Kecamatan Guntur Kabupaten Demak dilakukan dengan memberikan penyuluhan kesehatan, pemeriksaan kesehatan, praktek cuci tangan yang benar, senam bersama dan talkshow. Peserta adalah warga yang tinggal di desa Gaji yang diwakili oleh ibu/istri dari setiap KK yang merupakan Pasangan Usia Subur (PUS), jumlah peserta 60 orang yang diambil dengan teknik cluster random sampling. Lokasi kegiatan dilaksanakan di balai desa Gaji Kecamatan Guntur Kabupaten Demak. Data tentang pengetahuan diambil dengan kuesioner yang berisi 20 pertanyaan, dimana jawaban benar mendapat skor 1 dan jawaban salah mendapat skor 0. Data tentang sikap juga diambil dengan kuesioner yang terdiri dari 10 pertanyaan, dimana jawaban setuju mendapat skor 1 dan jawaban tidak setuju mendapat skor 0 .

Indikator keberhasilan kegiatan ini dilihat dari (1) Perbedaan skor nilai pretest dan postes pengetahuan dan sikap, (2) Penilaian Indek Keluarga Sehat (IKS) pada saat observasi awal dan pada saat evaluasi kegiatan. Hasil penghitungan IKS dikategorikan menjadi:
1) Nilai indeks $>0,800$
: keluarga sehat
2) Nilai indeks $0,500-0,800$ : keluarga pra-sehat
3) Nilai indeks $<0,500 \quad$ : keluarga tidak sehat

Proses pelaksanaan pengabdian masyarakat terdiri dari 3 tahapan, yaitu:

1. Tahap observasi

Melakukan observasi awal, yaitu mendata KK peserta, mendatangi rumah masingmasing peserta dan melakukan observasi/penilaian terhadap 12 indikator keluarga sehat. 
2. Tahap pelaksanaan kegiatan, yaitu:

a. Peserta diminta berkumpul di halaman Balai desa Gaji untuk dilakukan pemeriksaan kesehatan.

b. Peserta diminta senam bersama yang dipimpin oleh instruktur, hal ini untuk mengajarkan kepada peserta bahwa melakukan olah raga/aktifitas fisik sangat penting untuk kebugaran tubuh/kesehatan.

c. Selesai senam peserta diminta masuk ke balai desa Gaji dan peserta diberi lembar kuesioner pengetahuan dan sikap tentang PHBS, sebelum peserta mengisi kita jelaskan dulu bagaimana cara mengisi kuesioner, hasil jawaban peserta ini kita beri skor dan kita catat sebagai hasil pretes.

d. Peserta mendapatkan penyuluhan materi tentang PHBS tatanan rumah tangga dengan metode ceramah menggunakan media LCD dan tanya jawab sekitar 1 jam.

e. Peserta mengikuti praktek cuci tangan yang benar dengan 6 langkah yang dipimpin oleh instruktur.

f. Peserta mengikuti talkshow tentang perilaku hidup bersih dan sehat, seperti himbauan tidak merokok, melakukan olah raga secara rutin, membiasakan cuci tangan dengan sabun, membuang sampah ditempat sampah yang tertutup, memberi bayi ASI eksklusif, mengkonsumsi makanan dengan gizi seimbang, menimbang balita setiap bulan, bayi diberi imunisasi lengkap, dan lain-lain.

g. Peserta diberi lembar kuesioner pengetahuan dan sikap tentang PHBS, peserta diminta mengisi, hasil jawaban peserta kita beri skor dan kita catat sebagai hasil postes.

Skor pengetahun dan sikap pretes dan postes dibandingkan apakah ada perbedaan, apabila skor postes lebih tinggi jika dibandingkan dengan skor pretes maka dapat disimpulkan bahwa kegiatan pengabdian masyarakat ini berpengaruh terhadap peningkatan pengetahuan dan sikap tentang PHBS.

3. Tahap evaluasi

Evaluasi dilakukan setelah 3 bulan dari tahap pelaksanaan kegiatan, kita lakukan evaluasi dengan cara mendatangi rumah masing-masing peserta dan melakukan observasi terhadap 12 indikator keluarga sehat.

Hasil IKS yang diperoleh pada saat tahap observasi dan tahap evaluasi dibandingkan apakah ada perbedaan, apabila IKS pada tahap evaluasi lebih baik dibandingkan dengan tahap observasi, maka dapat disimpulkan bahwa kegiatan pengabdian masyarakat ini berpengaruh terhadap perilaku hidup bersih dan sehat (PHBS) peserta.

\section{HASIL DAN PEMBAHASAN}

Tabel 1. Skor pengetahuan tentang PHBS

sebelum dan sesudah kegiatan pengabdian masyarakat

\begin{tabular}{lccccccc}
\hline Pengetahuan & $\mathrm{N}$ & $\begin{array}{c}\text { Rerata skor } \\
\text { pengetahuan }\end{array}$ & $\begin{array}{c}\text { Standar } \\
\text { Deviasi } \\
(\mathrm{SD})\end{array}$ & $\begin{array}{c}\text { Skor } \\
\text { min }\end{array}$ & $\begin{array}{c}\text { Skor } \\
\text { maks }\end{array}$ & $\begin{array}{c}\text { Perbedaan } \\
\text { rerata skor }\end{array}$ & p-value \\
\cline { 1 - 3 } $\begin{array}{c}\text { Sebelum } \\
\text { kegiatan }\end{array}$ & 60 & 48,67 & 7,24 & 35 & 60 & 24,16 & 0,000 \\
\cline { 1 - 2 } $\begin{array}{c}\text { Sesudah } \\
\text { kegiatan }\end{array}$ & 72,83 & 7,15 & 60 & 85 & & \\
\hline
\end{tabular}


Tabel 1 menunjukkan bahwa rerata skor pengetahuan sebelum kegiatan adalah 48,67 dengan standar deviasi 7,24; sedang rerata skor pengetahuan sesudah kegiatan adalah 72,83 dengan standar deviasi 7,15. Hasil analisis diperoleh $p$-value $=0,000$, artinya pengetahuan tentang PHBS sesudah kegiatan secara bermakna mengalami peningkatan, dimana besar skor peningkatannya adalah 24,6.

Tabel 2. Skor sikap terhadap PHBS

sebelum dan sesudah kegiatan pengabdian masyarakat

\begin{tabular}{cccccccc}
\hline Sikap & $\mathrm{n}$ & $\begin{array}{c}\text { Rerata skor } \\
\text { sikap }\end{array}$ & $\begin{array}{c}\text { Standar } \\
\text { Deviasi } \\
(\mathrm{SD})\end{array}$ & $\begin{array}{c}\text { Skor } \\
\text { min }\end{array}$ & $\begin{array}{c}\text { Skor } \\
\text { maks }\end{array}$ & $\begin{array}{c}\text { Perbedaan } \\
\text { rerata skor }\end{array}$ & p-value \\
\cline { 1 - 5 } $\begin{array}{c}\text { Sebelum } \\
\text { kegiatan }\end{array}$ & 60 & 49,93 & 7,16 & 40 & 60 & 23,9 & 0,000 \\
\cline { 1 - 5 } $\begin{array}{l}\text { Sesudah } \\
\text { kegiatan }\end{array}$ & 73,83 & 8,46 & 60 & 90 & & \\
\hline
\end{tabular}

Tabel 2 menunjukkan bahwa rerata skor sikap sebelum kegiatan adalah 49,93 dengan standar deviasi 7,16; sedang rerata skor sikap sesudah kegiatan adalah 73,83 dengan standar deviasi 8,46. Hasil analisis diperoleh p-value $=0,000$, artinya sikap terhadap PHBS sesudah kegiatan secara bermakna mengalami peningkatan, dimana besar skor peningkatannya adalah 23,9 .

Tabel 3. Nilai IKS pada tahap observasi dan tahap evaluasi

\begin{tabular}{lcc}
\hline \multicolumn{1}{c}{ Nilai IKS } & Tahap Observasi & Tahap Evaluasi \\
\hline Keluarga Sehat & $20(33,33 \%)$ & $25(41,66)$ \\
Keluarga Pra Sehat & $25(41,67)$ & $30(50 \%)$ \\
Keluarga Tidak Sehat & $15(25 \%)$ & $5(8,34)$ \\
\hline
\end{tabular}

Tabel 3 menunjukkan bahwa nilai IKS pada tahap observasi keluarga yang mempunyai kategori keluarga sehat $20(33,33 \%)$, keluarga pra sehat $25(41,67 \%)$ dan keluarga tidak sehat 15.(25\%). Pada tahap evaluasi le; uarga yang mempunyai kategori keluarga sehat $25(41,66 \%)$, keluarga pra sehat $30(50 \%)$ dan keluarga tidak sehat $5(8,34 \%)$. Hasil analisis menunjukkan bahwa terdapat perbedaan nilai IKS pada tahap observasi awal dan tahap evaluasi, dimana prosentase keluarga sehat pada tahap evaluasi lebih besar dibandingkan dengan prosentase keluarga sehat pada tahap observasi awal.

Materi penyuluhan tentang PHBS yang disampaikan kepada peserta adalah fokus terhadap pokok-pokok PHBS tatanan rumah tangga yang meliputi: (1) persalinan dilakukan di faskes, (2) balita diberi ASI, (3) menimbang balita, (4) rumah bebas jentik, (5) cuci tangan menggunakan sabun, (6) tersedianya air bersih, (7) tersedia jamban sehat, (8) makan sayur dan buah setiap hari, (9) lakukan aktifitas fisik setiap hari, (10) tidak merokok. Materi tentang IKS yang terdiri dari 12 indikator yang meliputi: (1) keluarga mengikuti KB, (2) ibu bersalin di Faskes, (3) bayi mendapat imunissi dasar lengkap, (4) bayi diberi ASI eksklusif selama 6 bulan, (5) pertumbuhan balita ditimbang tiap bulan, (6) penderita TB paru berobat sesuai standar, (7) penderita hipertensi berobat teratur, (8) gangguan jiwa berat diobati dan tidak ditelantarkan, (9) tidak ada keluarga yang merokok, (10) keluarga memiliki/memakai air bersih, (11) keluarga memiliki/memakai jamban sehat, (12) Sekeluarga menjadi anggota JKN. 
Kegiatan penyuluhan kesehatan, praktek cuci tangan yang benar, dan talkshow dilakukan untuk mentransfer materi/ilmu pengetahuan tentang PHBS dan IKS kepada peserta agar terjadi peningkatan pengetahuan dan sikap untuk melaksanakan PHBS dengan tujuan tercapainya perubahan perilaku individu, keluarga dan masyarakat dalam membina dan memelihara perilaku sehat dan lingkungan sehat, serta berperan aktif dalam mewujudkan derajat kesehatan yang optimal.

Pemberdayaan masyarakat adalah bagian dari fungsi upaya kesehatan masyarakat (UKM) dari Puskesmas. Karena keluarga merupakan lembaga terkecil dari masyarakat, maka pemberdayaan masyarakat harus dimulai dari pemberdayaan keluarga (Kemenkes RI, 2011). Keluarga adalah suatu lembaga yang merupakan satuan (unit) terkecil dari masyarakat, terdiri atas ayah, ibu, dan anak (Marsanti, 2016). Keluarga yang seperti ini disebut rumah tangga atau keluarga inti (keluarga batih). Sedangkan keluarga yang anggotanya mencakup juga kakek dan atau nenek atau individu lain yang memi liki hubungan darah, bahkan juga tidak memiliki hubungan darah (misalnya pem bantu rumah tangga), disebut keluarga luas (extended family). Oleh karena meru pakan unit terkecil dari masyarakat, maka derajat kesehatan rumah tangga atau keluarga menentukan derajat kesehatan masyarakatnya. Sementara itu, derajat kesehatan keluarga sangat ditentukan oleh PHBS dari keluarga tersebut. Dengan demikian, inti dari pengembangan desa dan kelurahan ada lah memberdayakan keluarga-keluarga agar mampu mempraktikkan PHBS. PHBS adalah sekumpulan perilaku yang dipraktikkan atas dasar kesadaran sebagai hasil pembelajaran, yang menjadikan seseorang, keluarga, kelompok atau masyarakat mampu menolong dirinya sendiri (mandiri) di bidang kesehatan dan berperan aktif dalam mewujudkan kesehatan masyarakat. Di bidang pencegahan dan penanggulangan penyakit serta penyehatan lingkungan harus dipraktikkan perilaku mencuci tangan dengan sabun, menggunakan air bersih, menggunakan jam ban sehat, memberantas jentik nyamuk, tidak merokok di dalam ruangan, dan lain-lain. Di bidang kesehatan ibu dan anak serta keluarga berencana harus dipraktikkan perilaku meminta pertolongan persalinan di fasilitas kesehatan, menimbang balita dan memantau perkembangannya secara berkala, memberikan imunisasi dasar lengkap kepada bayi, menjadi aseptor keluarga berencana, dan lain-lain. Di bidang gizi dan farmasi harus dipraktikkan perilaku makan dengan gizi seimbang, minum Tablet Tambah Darah (TTD) selama hamil, memberi bayi Air Susu Ibu saja (ASI eksklusif), dan lain-lain (Kemenkes RI, 2011).

Pengetahuan merupakan salah satu faktor predisposisi untuk terjadinya perilaku, oleh karena itu untuk mendidik masyarakat agar mempunyai perilaku yang baik, warga perlu diberikan pengetahuan, kurangnya pengetahuan dapat berpengaruh pada tindakan yang dilakukan oleh seseorang (Zulaikhah, 2018). Upaya agar masyarakat berperilaku atau mengadopsi perilaku kesehatan dengan cara persuasi, bujukan, imbauan, ajakan, memberikan informasi, memberikan kesadaran dan sebagainya melalui pendidikan kesehatan atau penyuluhan kesehatan (Notoatmodjo, 2012). Penyuluhan kesehatan diartikan sebagai upaya penambahan pengetahuan dan kemampuan seseorang melalui teknik belajar atau instruksi dengan tujuan mengubah perilaku manusia secara individu, kelompok maupun masyarakat untuk dapat lebih mandiri dalam mencapai tujuan hidup sehat. Menurut L. Green faktor-faktor yang mempengaruhi perilaku, khususnya perilaku yang berhubungan dengan kesehatan adalah (1) faktor predisposisi (predisposing factors) yang terwujud dalam pengetahuan, sikap, kepercayaan, keyakinan dan sebagainya, (2) faktor pendukung (enabling factors) yng terwujud dalam linagkauangan fisik, tersedia atau tidak tersedianya sarana-sarana kesehatan, misalnya puskesmas, obat-obatan dan sebagainya, (3) faktor pendorong (reinforcing factors) yang terwujud dalam sikap dan perilaku petugas kesehatan, perilaku tokoh masyarakat (toma), tokoh agama (toga), undang-undang, peraturan, dan sebagainya (Notoatmodjo, 2012). Penyuluhan memberikan pengaruh terhadap pengetahuan, sikap dan praktek pencegahan DBD sehingga metode ini merupakan cara yang efektif untuk mencegah dan mengontrol penyakit (Zulaikhah, 
2018). Kegiatan senam bersama dilakukan kepada peserta sebagai upaya untuk memberikan contoh bahwa seseorang untuk hidup sehat harus melakukan aktifitas fisik setiap hari. Pemeriksaan kesehatan oleh tim medis dilakukan kepada peserta untuk skrening sehingga apabila kesehatan peserta mengalami gangguan sejak awal sudah diketahui dan segera diobati sehingga tidak menjadi lebih parah dan mengalami komplikasi.

\section{KESIMPULAN}

Kegiatan pengabdian masyarakat yang dilakukan melalui metode penyuluhan kesehatan, pemeriksaan kesehatan, praktek cuci tangan yang benar, senam bersama dan talkshow memberikan wawasan pentingnya pengetahuan tentang perilaku hidup bersih dan sehat bagi masyarakat di desa Gaji kecamatan Guntur Kabupaten Demak. Pengetahuan tentang PHBS mengalami kenaikan, pernyataan sikap untuk melaksanakan PHBS juga meningkat dan berdasarkan nilai IKS prosentase keluarga sehat juga mengalami peningkatan setelah pelaksanaan kegiatan pengabdian masyarakat.

\section{UCAPAN TERIMA KASIH}

Ucapan terima kasih disampaikan kepada LPPM UNISSULA yang telah memberikan dana, Kepala Desa Gaji dan warga yang bersedia menjadi peserta pada kegiatan pengabdian masyarakat ini.

\section{DAFTAR PUSTAKA}

Ahmadi, A. (2009), Psikologi Sosial, Rineka Cipta, Jakarta.

Dinas Kesehatan Demak (2016). Profil Kesehata Kabupaten Demak Tahun 2016. Dinas Kesehatan Demak.

Kemekes RI. (2016). Permenkes No. 39 tahun 2016 tentang Pedoman Penyelenggaraan Program Indonesia Sehat Dengan Pendekatan Keluarga, Kemenkes RI, Jakarta. pispk.kemkes.go.id, 20 Maret 2016.

Kemenkes RI. (2017). Buku Monitoring dan Evaluasi PIS-PK, pispk.kemkes.go.id, 28 Juni 2017.

Kemenkes RI. (2011). Permenkes No. 2269/MENKES/PER/XI/2011 tentang Pedoman Pembinaan Perilaku Hidup Bersih dan Sehat (PHBS).

Marsanti, A.S. (2016). Analisis capaian indikator keluarga sehat menggunakan metode Community Diagnosis di Desa Kleco, Kecamatan Bendo, Kabupaten Magetan", Skripsi, STIKes Bakti Husada Mulia Madiun.

Notoatmodjo, S. (2012). Promosi Kesehatandan Perilaku Kesehatan. Jakarta: RinekaCipta.

Pusdatin. (2018). Hasil Pendataan Keluarga Sehat dalam Aplikasi Keluarga Sehat. Pusat Data dan Informasi Kesehatan Republik Indonesia.

Priyoto. (2014). Teori sikap dan perilaku dalam kesehatan. Yogyakarta. Nuha Medika.

Sulastri, K., Nyoman, P.I., dan Suyasa, I.N., (2014). Hubungan Tingkat Pengetahuan Dengan Perilaku Anak Sekolah Tentang Hidup Bersih Dan Sehat di Sekolah Dasar Negeri Wilayah Puskesmas Selemadeg Timur. Jurnal kesehatan Lingkungan, 4(1), pp. 99-106.

Zulaikhah , S.T., Yusuf, I. (2018). Pengaruh Penyuluhan Terhadap Kepadatan Aedes Aegypti dalam Pencegahan Kejadian Luar Biasa Demam Berdarah. Jurnal Fakultas Kesehatan Masyarakat; 12(1):1-7. 